\title{
Causal association of circulating cholesterol levels with dementia: a mendelian randomization meta-analysis
}

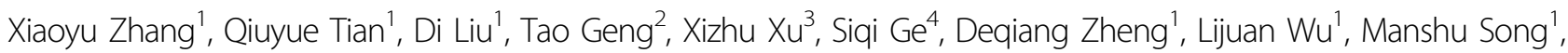 \\ Haifeng $\mathrm{Hou}^{3}$, Wei Wang $\mathbb{1 0}^{5}$ and Youxin Wang (1)
}

\begin{abstract}
Prospective studies have shown that abnormally circulating cholesterol is associated with the risk of dementia. However, whether the association is causal or not remains unclear. We attempt to infer the causal association in a MR meta-analysis by using ApoE gene polymorphisms as instrument variables. Studies with dementia risk (27 studies) or circulating lipid levels (7 studies) were included, with totally 3136 dementia patients and 3103 healthy controls. The analyses showed that carriers of $\varepsilon 2$ allele significantly were of decreased risk of $A D(O R=0.70 ; 95 \% \mathrm{Cl}$ : $0.58-0.84$; $P<$ $0.01)$, whereas carriers of $\varepsilon 4$ allele were of increased risk of $A D(O R=3.62 ; 95 \% \mathrm{Cl}: 3.03-4.32 ; P<0.05)$, compared to these of $\varepsilon 3$ allele. Circulating TC was significantly reduced in carriers of $\varepsilon 2$ allele (WMD $=-0.29 \mathrm{mmol} / \mathrm{L} ; 95 \% \mathrm{Cl}:-0.54$ to $-0.03 ; P<0.05)$ and increased in carriers of $\varepsilon 4$ allele (WMD $=0.42 \mathrm{mmol} / \mathrm{l} ; 95 \% \mathrm{Cl}: 0.001-0.84 ; P<0.05)$. In addition, carriers of $\varepsilon 4$ allele had reduction in circulating HDL-C (WMD $=-0.04 \mathrm{mmol} / \mathrm{L} ; 95 \% \mathrm{Cl}:-0.07$ to $-0.001 ; P<0.05)$. In comparing allele $\varepsilon 2$ with $\varepsilon 3$, the predicted OR of having AD for $1 \mathrm{mg} / \mathrm{dL}$ increment in circulating TC was $0.97(95 \% \mathrm{Cl}$ : 0.86-0.98; $P<0.05$ ). Comparing allele $\varepsilon 4$ with $\varepsilon 3$, the predicted OR for a $1 \mathrm{mg} / \mathrm{dL}$ increment in TC was 1.08 (95\% Cl: 1.05-17.58; $P<0.05$ ), and reduction in HDL-C was 2.30 (95\% Cl: 1.51-43.99; $P<0.05)$. Our findings demonstrate that high circulating TC and reduced HDL-C levels might be potential risk factors of the development of AD.
\end{abstract}

\section{Introduction}

Dementia is a syndrome caused by a variety of brain illnesses that have adverse impact on memory, thinking, behavior and the ability to perform daily activities. Alzheimer's disease (AD) and vascular dementia (VaD) account for more than $90 \%$ of the dementia cases ${ }^{1}$. The number of dementia patients currently is 47 million and estimated to 75 million by 2030 in globe ${ }^{2}$. The increasing burden of dementia emphasizes the necessity to identify risk factors underlying prevention of dementia.

Correspondence: Youxin Wang (wangy@ccmu.edu.cn)

${ }^{1}$ Department of Epidemiology and Health Statistics, School of Public Health, Beijing Municipal Key Laboratory of Clinical Epidemiology, Capital Medical University, Beijing 100069, China

${ }^{2}$ Geriatric Department, Emergency General Hospital, Beijing 100028, China

Full list of author information is available at the end of the article
Some prospective studies have revealed that circulating lipid abnormalities are independent indicators of the development of dementia ${ }^{3-7}$. In addition, dyslipidemia is a risk factor for vascular diseases, which is clearly associated with $\mathrm{VaD}$ and $\mathrm{AD}^{8}$. High total cholesterol (TC) levels were found to be positively associated with the risk of $A D$ in a dose-response manner ${ }^{9}$, while higher high-density lipoprotein cholesterol (HDL-C) $(>55 \mathrm{mg} / \mathrm{dL})$ resulted in decreased risk of $\mathrm{AD}^{10}$. However, confounding factors such as age and sex may also explain some of the observed associations, suggesting that the value is susceptible to confounding.

Differences in the amino acid sequence of apolipoprotein $\mathrm{E}$ (ApoE) are major determinants of plasma cholesterol levels within a population level. ApoE has a key role in the clearance of cholesterol from plasma ${ }^{11}$. It has been estimated that nearly $60 \%$ of circulating cholesterol

\section{(c) The Author(s) 2020}

(c) Open Access This article is licensed under a Creative Commons Attribution 4.0 International License, which permits use, sharing, adaptation, distribution and reproduction cc) in any medium or format, as long as you give appropriate credit to the original author(s) and the source, provide a link to the Creative Commons license, and indicate if changes were made. The images or other third party material in this article are included in the article's Creative Commons license, unless indicated otherwise in a credit line to the material. If material is not included in the article's Creative Commons license and your intended use is not permitted by statutory regulation or exceeds the permitted use, you will need to obtain permission directly from the copyright holder. To view a copy of this license, visit http://creativecommons.org/licenses/by/4.0/. 
variation is under genetic control and thereout $14 \%$ variation is ascribed to $A p o E$ genetic defects ${ }^{12}$. The synthesis of ApoE is controlled by three independent alleles such as $\varepsilon 2$, $\varepsilon 3$ and $\varepsilon 4$, corresponding to 6 ApoE genotypes ( $\varepsilon 2 \varepsilon 2$, $\varepsilon 3 \varepsilon 2$, $\varepsilon 4 \varepsilon 2$, $\varepsilon 3 \varepsilon 3, \varepsilon 4 \varepsilon 3$ and $\varepsilon 4 \varepsilon 4)^{13}$. Genotypes $\varepsilon 4 / \varepsilon 4$ and $\varepsilon 4 / \varepsilon 3$ are associated with high cholesterol concentration in blood ${ }^{14-17}$. In addition, polymorphisms of the ApoE gene have been studied extensively in the context of a variety of clinical endpoints such as hypercholesterolemia $^{18,19}$, ischemic heart disease ${ }^{20,21}$, stroke ${ }^{22}$ and hypertension ${ }^{23,24}$.

In the absence of trials, genetic studies can be used to help evaluate causality. This approach is known as Mendelian randomization (MR) which can be used to assess gene-related risk factors for causal associations with clinical outcomes. MR analyses are based on Mendel's observation that inheritance of one trait should be independent of the inheritance of other traits ${ }^{25}$. To test this hypothesis and provide an unbiased estimation of the causality, MR meta-analysis was used to assess the causality between circulating lipid profiles and the risk of dementia.

\section{Materials and Methods}

The present meta-analysis was undertaken in accordance with the guidelines formulated in the Preferred Reporting Items for Systematic Reviews and Metaanalyses (PRISMA) statement ${ }^{26}$.

\section{Search strategy for qualified studies}

To identify all relevant articles that addressed the associations of $A p o E$ gene $\varepsilon 2 / \varepsilon 3 / \varepsilon 4$ polymorphism with dementia or circulating lipid changes, we systematically searched PubMed and the Excerpta Medica database (EMBASE) for literature in the English language. For the research strategy, logic based on specific descriptors was adopted (English language) in combination with Boolean operators (and/or), with the aid of parentheses to define intercalation within the same logic and the quotation marks to identify the compound words. The search was conducted using the following search terms: (APOE, "Apolipoprotein E" or "apo-E") and (polymorphism, allele, variant, variation, genotype, mutation, SNP or isoforms) and (dementia, "Alzheimer"” or "vascular dementia") and ("lipid profile", "total cholesterol", triglyceride, triacylglycerol, "high-density lipoprotein cholesterol", "low-density lipoprotein cholesterol", TC, "HDL-C", "LDL-C" or TG). All selected articles were written in English and published before 20 June 2019. In addition, we manually scrutinized the reference list of eligible literature.

The titles and abstracts of all retrieved articles were read independently by two authors (Xiaoyu Zhang and Qiuyue Tian). For articles that could not be ascertained, the full text and supplementary data were reviewed. The process was conducted independently by the two authors. The discrepancy was adjudicated by a discussion with the third author (Di Liu).

\section{Inclusion and exclusion criteria}

The literatures that met the following criteria were included in the meta-analysis: 1) detailed allele or genotype counts of $A p o E \varepsilon 2 / \varepsilon 3 / \varepsilon 4$ gene polymorphism should be available between dementia patients and controls in case-control studies (including nested case-control studies); 2) the mean or median values (standard deviations) on TC, HDL-C, LDL-C and triglyceride (TG) levels were found across $A p o E$ gene $\varepsilon 2 / \varepsilon 3 / \varepsilon 4$ alleles or genotypes in case-control (including nested case-control) or cohort studies.

The exclusion criteria were as follows: 1) studies that examined the progression, severity or response to treatment of dementia in association with ApoE gene $\varepsilon 2 / \varepsilon 3 / \varepsilon 4$ polymorphism or a lack of healthy controls; 2) case reports or series, editorials, narrative or systematic reviews, conference abstracts or proceedings and nonEnglish articles.

\section{Literature quality assessment}

The Newcastle-Ottawa Scale was used to assess the methodological quality of the included studies ${ }^{27}$. For casecontrol studies, this comprised the determination of (1) adequate case definition, (2) representativeness of cases, (3) selection of control, (4) definition of control, (5) comparability of case and control groups, (6) exposure, (7) whether there were identical exposure methods for cases and controls, and (8) non-response rate. For cohort studies, this comprised the determination of (1) representativeness of the exposed cohort, (2) selection of the unexposed cohort, (3) exposure, (4) whether the study subjects had an ending event that occurred before the study began, (5) comparability of the cohorts, (6) evaluation of the ending event, (7) whether follow-up was sufficient, and (8) integrity of follow-up examinations. Each item that met one of the above-mentioned criteria was represented by $*$, and each $*$ was equivalent to 1 point, giving a potential total of 9 points. Higher scores indicated higher quality studies. Moreover, studies with a score of 6 points and above were included in the present meta-analysis.

\section{Extracted information}

Data including the first author's last name, publication year, ethnicity, dementia subtype, sample size, allele counts of ApoE gene $\varepsilon 2 / \varepsilon 3 / \varepsilon 4$ polymorphisms between dementia patients and controls, the mean or median (standard deviation) values of TC, TG, HDL-C and LDL$C$ levels across $A p o E$ gene $\varepsilon 2 / \varepsilon 3 / \varepsilon 4$ carriers were extracted independently from each qualified study by two 


\begin{tabular}{|c|c|c|c|c|c|c|c|}
\hline Author(Year) & $\varepsilon 2$-case & $\varepsilon 2$-control & $\varepsilon 3$-case & $\varepsilon 3$-control & weight(\%) & OR (95\%Cl) & \\
\hline Shafagoj,Y.A.(2018) & 4 & 3 & 60 & 60 & 1.53 & $1.31(0.31-5.63)$ & \\
\hline Wang, C(2018) & 4 & 15 & 34 & 57 & 3.47 & $0.50(0.18-1.42)$ & \\
\hline Sery, O.(2017) & 63 & 66 & 666 & 562 & $5.80 \%$ & $0.82(0.59-1.14)$ & $\mapsto$ \\
\hline Lara,V.P.(2016) & 10 & 40 & 74 & 234 & 4.32 & $0.81(0.43-1.56)$ & $\longmapsto$ \\
\hline Agarwal,R.(2015) & 0 & 9 & 24 & 29 & 1.68 & $0.08(0.005-1.35)$ & \\
\hline de-Almada, B.V.(2012) & 7 & 28 & 99 & 280 & 4.83 & $0.73(0.33-1.61)$ & $\longmapsto$ \\
\hline Singh, N.K.(2012) & 6 & 10 & 90 & 129 & 3.33 & $0.87(0.33-2.31)$ & \\
\hline Warren, M. W.(2012) & 6 & 24 & 57 & 121 & 4.63 & $0.58(0.25-1.33)$ & -1 \\
\hline Styczynska, M.(2009) & 6 & 9 & 100 & 148 & 3.95 & $0.99(0.36-2.69)$ & \\
\hline Bednarska-Makaruk, M.(2009) & 9 & 9 & 56 & 68 & 3.9 & $1.18(0.50-2.81)$ & \\
\hline Pandey, P.(2007) & 6 & 24 & 181 & 287 & 3.45 & $0.41(0.17-1.00)$ & $\longrightarrow$ \\
\hline Jasinska-Myga, B.(2007) & 16 & 17 & 144 & 145 & 4.31 & $0.95(0.50-1.82)$ & $\longmapsto$ \\
\hline Raygani,A.V.(2006) & 2 & 6 & 144 & 201 & 3.75 & $0.47(0.10-2.31)$ & \\
\hline Kapur, S.(2006) & 5 & 12 & 7 & 29 & 1.41 & $1.42(0.63-3.24)$ & \\
\hline Wehr, H. (2006) & 9 & 14 & 131 & 240 & 4.5 & $1.16(0.52-2.63)$ & \\
\hline Wehr,H.(2006) & 5 & 14 & 107 & 240 & 3.75 & $0.81(0.30-2.19)$ & \\
\hline Wehr,H.(2006) & 6 & 14 & 92 & 240 & 3.96 & $1.11(0.44-2.81)$ & \\
\hline Nacmias, B.(2004) & 7 & 7 & 113 & 124 & 3.56 & $1.09(0.39-3.02)$ & \\
\hline Bosco, $\mathrm{P}(2004)$ & 5 & 16 & 233 & 240 & 4.06 & $0.34(0.13-0.90)$ & \\
\hline Panza, F. (2003) & 2 & 12 & 39 & 30 & 1.57 & $0.17(0.04-0.72)$ & $\longrightarrow$ \\
\hline Paragh, G.(2002) & 1 & 3 & 18 & 32 & 1.77 & $0.61(0.07-5.50)$ & \\
\hline Paragh, G.(2002) & 1 & 3 & 31 & 32 & 1.71 & $0.37(0.04-3.33)$ & \\
\hline Tranykov, L.(2002) & 13 & 15 & 278 & 84 & 3.32 & $0.30(0.15-0.60)$ & \\
\hline Tranykov, L.(2002) & 3 & 15 & 78 & 84 & 2.34 & $0.24(0.07-0.82)$ & \\
\hline Tranykov, L.(2002) & 6 & 15 & 86 & 84 & 2.97 & $0.43(0.17-1.06)$ & \\
\hline Dupuy, A.M. (2001) & 6 & 9 & 107 & 150 & 3.71 & $0.94(0.34-2.56)$ & \\
\hline Isbir, T.(2001) & 3 & 1 & 59 & 56 & 0.69 & $2.76(0.30-25.76)$ & \\
\hline González, C. (1999) & 1 & 3 & 5 & 39 & 1.79 & $2.33(0.29-18.97)$ & 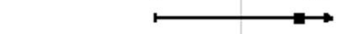 \\
\hline Fernandes, M.A.(1999) & 2 & 2 & 40 & 28 & 1.79 & $0.71(0.11-4.79)$ & $\longrightarrow$ \\
\hline Wieringa, G. E.(1997) & 1 & 2 & 24 & 25 & 1.79 & $0.54(0.05-5.60)$ & \\
\hline Wieringa, G. E.(1997) & 1 & 2 & 10 & 25 & 1.33 & $1.23(0.12-12.19)$ & \\
\hline Metzger, R.E.(1996) & 0 & 1 & 7 & 9 & 0.34 & $0.46(0.02-9.86)$ & \\
\hline Janvik, G.P.(1995) & 9 & 24 & 126 & 215 & 4.69 & $0.66(0.32-1.39)$ & $\longmapsto$ \\
\hline \multirow[t]{2}{*}{ pooled OR } & & & & & 100 & $0.69(0.59-0.81)$ & Her \\
\hline & & & & & & & 0.851 .653 .25 \\
\hline
\end{tabular}

investigators (Xiaoyu Zhang and Qiuyue Tian). The units of circulating TG, TC, HDL-C and LDL-C were consistently standardized to millimole per liter $(\mathrm{mmol} / \mathrm{L})$. The following data collection and article quality were assessed in duplicate.

\section{Statistical analyses}

Data management and statistical analyses were performed with Stata software (StataCorp, TX, USA, version 12.0 for Windows). The odds ratios (ORs) and 95\% confidence intervals (CIs) were calculated to express the distributional differences of alleles of $A p o E$ gene $\varepsilon 2 / \varepsilon 3 / \varepsilon 4$ polymorphism between patients with dementia and the controls. Weighted mean differences (WMDs) and 95\% CIs were calculated to compare the changes in circulating levels of TC, TG, HDL-C and LDL-C across allele carriers.

In this meta-based MR analysis, if the $I^{2}$ values were $<50 \%$, then the fixed effects model was selected to calculate the pooled ORs and $95 \% \mathrm{CI}^{28}$. Otherwise, a random effects model was applied to combine effect-size estimates. Predetermined subgroup analyses were undertaken prior in terms of dementia subtype ( $\mathrm{AD}$ and $\mathrm{VaD}$ ), sample size, ethnicity or gender. The probability of publication bias was determined visually by Begg's funnel plot and Egger's regression asymmetry test.
Under the assumptions of MR, we calculated the risk prediction as a ratio of the coefficient for the association between $A p o E$ gene $\varepsilon 2 / \varepsilon 3 / \varepsilon 4$ polymorphism and dementia risk to that of the relationship between the polymorphism and circulating lipid changes. Statistical significance was considered when a two-tailed $P$ value was less than 0.05 .

\section{Results}

\section{Eligibility criteria}

The flow chart of the selection process was shown in Supplementary Fig. S1. For the association between $A p o E$ gene polymorphism $\varepsilon 2 / \varepsilon 3 / \varepsilon 4$ and dementia, there were 27 studies with 3136 dementia patients and 3103 healthy controls $^{29-41}$. For the association between ApoE gene $\varepsilon 2 /$ $\varepsilon 3 / \varepsilon 4$ polymorphism and circulating cholesterol, five studies addressed HDL- $\mathrm{C}^{35,42-45}$, five studies addressed LDL-C $\mathrm{C}^{35,42-45}$, seven studies addressed $\mathrm{TG}^{35,42-47}$ and six studies addressed $\mathrm{TC}^{35,42-46}$, were included.

\section{Association of the ApoE gene alleles with dementia}

Considering the limited numbers of $A p o E$ genotypes, only allelic comparisons ( $\varepsilon 2$ versus $\varepsilon 3$, and $\varepsilon 4$ versus $\varepsilon 3$ ) were computed. As shown in Fig. 1, carriers of $\varepsilon 2$ allele were of a significant decrease risk for dementia $(O R=0.69$; 


\begin{tabular}{|c|c|c|c|c|c|c|c|}
\hline Author(Year) & $\varepsilon 3$-case & $\varepsilon 3$-control & $\varepsilon 4$-case & $\varepsilon 4$-control & weight(\%) & OR (95\%Cl) & \\
\hline Shafagoj,Y.A.(2018) & 60 & 60 & 12 & 3 & $1.53 \%$ & $4.00(1.07-14.90)$ & \\
\hline Wang, C(2018) & 34 & 57 & 52 & 18 & $3.47 \%$ & $4.84(2.44-9.60)$ & $\longmapsto$ \\
\hline Sery, O.(2017) & 666 & 562 & 261 & 94 & $5.80 \%$ & $2.34(1.81-3.04)$ & $=1$ \\
\hline Lara,V.P.(2016) & 74 & 234 & 34 & 42 & $4.32 \%$ & $2.56(1.52-4.32)$ & $\mapsto$ \\
\hline Agarwal,R.(2015) & 24 & 29 & 14 & 4 & $1.68 \%$ & $4.23(1.23-14.55)$ & $\longmapsto$ \\
\hline de-Almada, B.V.(2012) & 99 & 280 & 58 & 56 & $4.83 \%$ & $2.93(1.90-4.52)$ & $\mapsto$ \\
\hline Singh, N.K. (2012) & 90 & 129 & 44 & 11 & $3.33 \%$ & $5.73(2.81-11.71)$ & \\
\hline Warren, M. W.(2012) & 57 & 121 & 85 & 52 & $4.63 \%$ & $3.47(2.18-5.54)$ & $\longmapsto$ \\
\hline Bednarska-Makaruk, M.(2009) & 56 & 68 & 49 & 25 & $3.95 \%$ & $3.74(2.08-6.74)$ & $\longmapsto$ \\
\hline Styczynska, M.(2008) & 100 & 148 & 48 & 19 & $3.90 \%$ & $2.38(1.30-4.33)$ & $\mapsto$ \\
\hline Pandey, P.(2007) & 181 & 287 & 27 & 13 & $3.45 \%$ & $3.29(1.66-6.55)$ & $\longmapsto$ \\
\hline Jasinska-Myga, B.(2007) & 144 & 145 & 32 & 38 & $4.31 \%$ & $0.85(0.50-1.43)$ & $\theta$ \\
\hline Raygani,A.V.(2006) & 144 & 201 & 42 & 15 & $3.75 \%$ & $3.91(2.09-7.32)$ & $\longmapsto$ \\
\hline Kapur, S.(2006) & 7 & 29 & 8 & 5 & $1.41 \%$ & $6.63(1.65-26.59)$ & \\
\hline Wehr, H. (2006) & 131 & 240 & 58 & 30 & $4.50 \%$ & $3.54(2.17-5.78)$ & $\mapsto$ \\
\hline Wehr,H.(2006) & 107 & 240 & 18 & 30 & $3.75 \%$ & $1.35(0.72-2.52)$ & $H$ \\
\hline Wehr,H. (2006) & 92 & 240 & 24 & 30 & $3.96 \%$ & $2.09(1.16-3.76)$ & $\mapsto$ \\
\hline Nacmias, B.(2004) & 113 & 124 & 46 & 13 & $3.56 \%$ & $3.88(1.99-7.56)$ & $\longmapsto$ \\
\hline Bosco, $\mathrm{P}(2004)$ & 233 & 240 & 76 & 16 & $4.06 \%$ & $4.89(2.77-8.64)$ & $\longmapsto$ \\
\hline Panza, F.(2003) & 39 & 30 & 8 & 4 & $1.57 \%$ & $1.54(0.42-5.60)$ & $\leftrightarrow$ \\
\hline Paragh, G.(2002) & 18 & 32 & 12 & 5 & $1.77 \%$ & $4.27(1.30-14.06)$ & $\longmapsto$ \\
\hline Paragh, G.(2002) & 31 & 32 & 8 & 5 & $1.71 \%$ & $1.65(0.49-5.60)$ & $\leftrightarrow$ \\
\hline Tranykov, L.(2002) & 278 & 84 & 147 & 9 & $3.32 \%$ & $4.94(2.41-10.10)$ & ఐ \\
\hline Tranykov, L.(2002) & 78 & 84 & 9 & 9 & $2.34 \%$ & $1.08(0.41-2.85)$ & 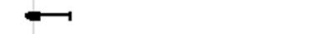 \\
\hline Tranykov, L.(2002) & 86 & 84 & 32 & 9 & $2.97 \%$ & $3.47(1.56-7.72)$ & $\longmapsto$ \\
\hline Dupuy, A.M.(2001) & 107 & 150 & 30 & 18 & $3.71 \%$ & $2.34(1.24-4.41)$ & $\longmapsto$ \\
\hline Isbir, T.(2001) & 59 & 56 & 8 & 1 & $0.69 \%$ & $7.59(0.92-62.68)$ & \\
\hline González, C.(1999) & 5 & 39 & 34 & 9 & $1.79 \%$ & $29.47(9.00-96.47)$ & \\
\hline Fernandes, M.A.(1999) & 40 & 28 & 18 & 4 & $1.79 \%$ & $3.15(0.96-10.32)$ & $\longmapsto$ \\
\hline Wieringa, G. E.(1997) & 24 & 25 & 12 & 5 & $1.79 \%$ & $2.50(0.77-8.17)$ & $\longmapsto$ \\
\hline Wieringa, G. E.(1997) & 10 & 25 & 5 & 5 & $1.33 \%$ & $2.50(0.59-10.56)$ & $\longleftrightarrow$ \\
\hline Metzger, R.E.(1996) & 7 & 9 & 3 & 0 & $0.34 \%$ & $8.87(0.39-199.60)$ & \\
\hline Javik, G.P.(1995) & 126 & 215 & 71 & 36 & $4.69 \%$ & $3.37(2.13-5.32)$ & $\mapsto$ \\
\hline \multirow[t]{2}{*}{ pooled OR } & & & & & $100 \%$ & $3.06(2.54-3.68)$ & $\mathbf{H a r}$ \\
\hline & & & & & & & 0.62 .64 .66 .68 .610 .612 .614 .6 \\
\hline
\end{tabular}

95\% CI: 0.59 to $0.81 ; P<0.01)$ compared to these of $\varepsilon 3$ allele, with a low probability of publication bias as reflected by the suggestive symmetry of the funnel plot (Supplementary Fig. S2) and the Egger's test $(P=0.364)$. There was no evidence of heterogeneity for the comparison of $\varepsilon 2$ with $\varepsilon 3\left(I^{2}=8.30 \%\right)$. In contrast, the $\varepsilon 4$ allele was significantly associated with a 3.06 -fold $(\mathrm{OR}=3.06$; 95\% CI: 2.54-3.68; $P<0.01$; Fig. 2) increased risk of developing dementia compared with the $\varepsilon 3$ allele, accompanied by moderate heterogeneity $\left(I^{2}=55.10 \% ; P\right.$ $<0.01$; Supplementary Fig. S3). In addition, there was no apparent publication bias (Egger's test: $P=0.131$ ), which improved the strength of this association.

\section{Stratified comparisons for dementia risk}

In an attempt to examine the potential sources of heterogeneity between different subgroups, several subgroup analyses were conducted according to the dementia type, sample size, ethnicity or gender (Table 1).

The summary effect estimates in stratified analyses were similar in meta-analysis including studies with sample size $\geq 200$ (OR $=0.68,95 \% \mathrm{CI}: 0.56-0.85 ; P<0.05$ ) and sample size $<200$ (OR $=0.70,95 \%$ CI: $0.49-0.99 ; P<0.05)$ across the comparison of $\varepsilon 2$ vs. $\varepsilon 3$. In addition, the summary effect estimates were also comparable in meta-analysis including studies with sample size $\geq 200$ (OR $=3.05$, 95\% CI: 2.54-6.67; $P<0.01)$ and sample size $<200 \quad(\mathrm{OR}=3.25,95 \% \mathrm{CI}$ : $2.19-4.83 ; P<0.01)$ across the comparison of $\varepsilon 4$ vs. $\varepsilon 3$. In the subgroup analyses by dementia subtypes, the association of the $A p o E$ gene with the risk of $\mathrm{AD}(\mathrm{OR}=3.62$; 95\% CI: $3.03-4.32 ; P<0.01)$ was stronger across the comparison of $\varepsilon 4$ vs. $\varepsilon 3$. Carriers with the $\varepsilon 2$ allele had a significant decreased risk in patients with $\mathrm{AD}(\mathrm{OR}=0.70$; $95 \% \mathrm{CI}$ : 0.58-0.84; $P<$ $0.01)$ compared to these with the $\varepsilon 3$ allele.

In terms of $\mathrm{AD}$, carriers with the $\varepsilon 4$ allele were of increased risk in Caucasian (OR $=3.53,95 \% \mathrm{CI}$ : 2.62-4.78; $P<0.01)$, Asian (OR = 4.76, 95\% CI: 3.39-6.69; $P<0.01)$, Latinos (OR $=2.93,95 \%$ CI: $1.90-4.52 ; P<0.01)$ and North America (OR $=3.45$, 95\% CI: $2.49-4.78 ; P<0.01$ ), compared to carriers with the $\varepsilon 3$ allele. There were consistently significant associations for the comparison of $\varepsilon 2$ versus $\varepsilon 3$ in the male (OR $=0.76$; 95\% CI: 0.64-0.92; $P<0.01)$ and female $(\mathrm{OR}=0.74$; 95\% CI: $0.64-0.86 ; P<0.01)$ in term of AD.

\section{Association of the ApoE gene alleles with circulating cholesterols levels}

In the view of limited data on $A p o E$ genotypes, mean lipid changes were only compared in $\varepsilon 2$ vs. $\varepsilon 3$ and $\varepsilon 4$ vs. $\varepsilon 3$. 
Table 1 Subgroup analyses of the $A p o E$ gene $\varepsilon 2 / \varepsilon 3 / \varepsilon 4$ polymorphism with dementia risk.

\begin{tabular}{|c|c|c|c|c|c|c|c|c|c|}
\hline \multirow[b]{2}{*}{ Subgroup } & \multirow[b]{2}{*}{ Studies, $\mathbf{n}$} & \multicolumn{4}{|c|}{$\varepsilon 2$ vs. $\varepsilon 3$} & \multicolumn{4}{|c|}{$\varepsilon 4$ vs. $\varepsilon 3$} \\
\hline & & OR & $95 \% \mathrm{Cl}$ & $P$ & $I^{2}$ & OR & $95 \% \mathrm{Cl}$ & $P$ & $I^{2}$ \\
\hline \multicolumn{10}{|l|}{ Dementia type } \\
\hline$A D$ & 23 & 0.70 & $0.58-0.84$ & $<0.01$ & $13.10 \%$ & 3.62 & $3.03-4.32$ & $<0.01$ & $32.40 \%$ \\
\hline $\mathrm{VaD}$ & 3 & 0.44 & $0.18-1.07$ & 0.07 & $20.6 \%$ & 1.32 & $0.81-2.13$ & 0.27 & $0.00 \%$ \\
\hline \multicolumn{10}{|l|}{ Total sample size } \\
\hline$<200$ & 19 & 0.70 & $0.49-0.99$ & $<0.05$ & $13.10 \%$ & 3.25 & $2.19-4.83$ & $<0.01$ & $66.10 \%$ \\
\hline$\geq 200$ & 14 & 0.68 & $0.56-0.85$ & $<0.05$ & $9.70 \%$ & 3.05 & $2.54-3.67$ & $<0.01$ & $54.40 \%$ \\
\hline \multicolumn{10}{|c|}{ Ethnicity in AD patients } \\
\hline Caucasian & 12 & 0.65 & $0.43-0.96$ & $<0.05$ & $36.40 \%$ & 3.53 & $2.62-4.78$ & $<0.01$ & $56.90 \%$ \\
\hline Asian & 7 & 0.80 & $0.43-1.51$ & 0.50 & $19.30 \%$ & 4.76 & $3.39-6.69$ & $<0.01$ & $0.00 \%$ \\
\hline Latinos & 1 & 0.71 & $0.30-1.67$ & 0.43 & $0.00 \%$ & 2.93 & $1.90-4.52$ & $<0.01$ & $0.00 \%$ \\
\hline North America & 3 & 0.59 & $0.32-1.07$ & 0.08 & $0.00 \%$ & 3.45 & $2.49-4.78$ & $<0.01$ & $0.00 \%$ \\
\hline \multicolumn{10}{|c|}{ Gender in AD patients } \\
\hline Male & 1 & 0.76 & $0.64-0.92$ & $<0.01$ & $100 \%$ & 1.00 & $0.92-1.10$ & 0.90 & $100 \%$ \\
\hline Female & 1 & 0.74 & $0.64-0.86$ & $<0.01$ & $100 \%$ & 1.00 & $0.95-1.13$ & 0.38 & $100 \%$ \\
\hline
\end{tabular}

Bold values were statistically significant differences for subgroup analyses $(P<0.05)$.

Figures 3 and 4 present the overall analyses of the ApoE gene $\varepsilon 2 / \varepsilon 3 / \varepsilon 4$ polymorphism with circulating levels of TC, HDL-C, LDL-C, and TG under $\varepsilon 2$ vs. $\varepsilon 3$ and $\varepsilon 4$ vs. $\varepsilon 3$ comparisons. Carriers of $\varepsilon 2$ allele had a significant reduction in circulating TC $(\mathrm{WMD}=-0.29 \mathrm{mmol} / \mathrm{L}$; 95\% CI: -0.54 to $-0.03 ; P<0.05$; Fig. 3) when compared to $\varepsilon 3$ allele, with the moderate evidence of heterogeneity $\left(I^{2}=50 \%\right)$. In addition, carriers of the $\varepsilon 4$ allele had a significant reduction in circulating $\mathrm{HDL}-\mathrm{C}(\mathrm{WMD}=$ $-0.04 \mathrm{mmol} / \mathrm{L} ; 95 \% \mathrm{CI}:-0.08$ to $-0.001 ; P<0.05)$ without heterogeneity $\left(I^{2}=0.00 \%\right)$, compared to carriers of the $\varepsilon 3$ allele. As expected, higher circulating TC was observed in subjects with the $\varepsilon 4$ allele $(\mathrm{WMD}=$ $0.42 \mathrm{mmol} / \mathrm{l} ; 95 \%$ CI: $0.001-0.84 ; P<0.05$; Fig. 4) compared to the $\varepsilon 3$ allele carriers, with a significant heterogeneity $\left(I^{2}=91.70 \%\right)$.

\section{Causal prediction of circulating lipids for dementia}

According to the requirements of MR approach, the predicted OR of having AD for $1 \mathrm{mg} / \mathrm{dL}$ increment in circulating TC was 0.97 (95\% CI: $0.86-0.98 ; P<0.05)$ for the comparison of allele $\varepsilon 2$ with $\varepsilon 3$. In comparing allele $\varepsilon 4$ with $\varepsilon 3$, the predicted OR for a $1 \mathrm{mg} / \mathrm{dL}$ increment in TC was 1.08 (95\% CI: $1.05-17.58 ; P<0.05)$, while the predicted OR for a $1 \mathrm{mg} / \mathrm{dL}$ reduction in HDL-C was 2.30 (95\% CI: $1.51-43.99 ; P<0.05)$. This estimate was significant at a significance level of $5 \%$, and the null hypothesis value of 1 was not included in the estimated 95\% CI for the association of circulating cholesterol level and risk of dementia.

\section{Discussion}

In this MR meta-analysis, $A p o E$ gene polymorphism was utilized as an instrumental variable to evaluate the potential causal relation between circulating cholesterol and the risk of dementia. To the best of our knowledge, this is the first meta-analysis to evaluate the relationship from the perspective of the MR approach.

Cholesterol in the pathogenesis of $\mathrm{AD}$ remains controversial $^{48}$. The lipid-AD associations are progressively stronger with increasing pathological certainty of an AD diagnosis. These relationships were still significant after adjustment for the ApoE genotype and for other known risk factors ${ }^{3}$. In addition, it is still unclear that this association is causal or confouder, because of the involvement of many confounding factors including age, BMI and genetic background, as well as the complex biological effects of circulating lipid levels. Therefore, the MR approach is used to assess the causal relation of circulating cholesterol levels with dementia risk.

Some evidence supported a close relation between ApoE genetic alterations and the circulating HDL-C and TC profiles in the meta-analyses ${ }^{24,49-51}$, which revealed that the $A p o E$ gene $\varepsilon 4$ allele was significantly associated with reduced circulating HDL-C and increased circulating TC levels. Previous MR meta-analyses have assessed the association between genetically circulating cholesterol levels and other diseases including cancer and hypertension. Yang et al. indicated that the predicted odds of overall cancer for a $1 \mathrm{mg} / \mathrm{dL}$ reduction in circulating 


\begin{tabular}{|c|c|c|c|c|c|c|c|c|c|}
\hline Author(Year) & $N(\varepsilon 2)$ & Mean(ع2) & $\mathrm{SD}(\varepsilon 2)$ & $N(\varepsilon 3)$ & Mean $(\varepsilon 3)$ & $S D(\varepsilon 3)$ & weight(\%) & WMD $(95 \% \mathrm{Cl})$ & \\
\hline $\begin{array}{l}\text { HDL-C } \\
\text { Periyasamy, S.(2017) } \\
\text { Periyasamy, S.(2017) } \\
\text { Singh, N.K. (2012) } \\
\text { Singh, N.K.(2012) } \\
\text { Cacabelos, R. (2004) } \\
\text { Cacabelos, R.(2004) } \\
\text { Moreno, J.A.(2004) } \\
\text { Pallaud,C. (2001) } \\
\text { Pooled WMD }\end{array}$ & $\begin{array}{r}5 \\
3 \\
4 \\
9 \\
4 \\
7 \\
10 \\
111\end{array}$ & $\begin{array}{l}1.08 \\
0.97 \\
1.15 \\
1.16 \\
1.45 \\
1.44 \\
1.18 \\
1.33\end{array}$ & $\begin{array}{l}0.21 \\
0.19 \\
0.11 \\
0.34 \\
0.28 \\
0.44 \\
0.34 \\
0.35\end{array}$ & $\begin{array}{r}42 \\
117 \\
23 \\
55 \\
55 \\
62 \\
66 \\
493\end{array}$ & $\begin{array}{l}1.12 \\
1.07 \\
1.07 \\
1.21 \\
1.43 \\
1.37 \\
1.28 \\
1.25\end{array}$ & $\begin{array}{l}0.17 \\
0.15 \\
0.18 \\
0.23 \\
0.42 \\
0.4 \\
0.35 \\
0.32\end{array}$ & $\begin{array}{r}4.35 \\
4.14 \\
4.79 \\
4.03 \\
3.5 \\
3.15 \\
4.06 \\
53.11 \\
3.14\end{array}$ & $\begin{array}{r}-0.04(-0.23,0.15) \\
-0.1(-0.32,0.12) \\
0.08(-0.05,0.21) \\
-0.05(-0.28,0.18) \\
0.02(-0.28,0.32) \\
0.07(-0.27,0.41) \\
-0.1(-0.33,0.13) \\
0.08(-01,0.15) \\
0.04(-0.01,0.09)\end{array}$ & $=$ \\
\hline $\begin{array}{l}\text { LDL-C } \\
\text { Periyasamy, S. (2017) } \\
\text { Periyasamy, S.(2017) } \\
\text { Singh, N.K. (2012) } \\
\text { Singh, N.K.(2012) } \\
\text { Cacabelos, R. (2004) } \\
\text { Cacabelos, R.(2004) } \\
\text { Moreno, J.A.(2004) } \\
\text { Pallaud, C.(2001) } \\
\text { Pooled WMD }\end{array}$ & $\begin{array}{r}5 \\
3 \\
4 \\
9 \\
4 \\
7 \\
10 \\
111\end{array}$ & $\begin{array}{l}2.94 \\
3.46 \\
1.93 \\
2.05 \\
2.86 \\
3.33 \\
2.11 \\
3.66\end{array}$ & $\begin{array}{l}0.61 \\
1.6 \\
0.11 \\
0.67 \\
0.74 \\
1.05 \\
0.46 \\
0.87\end{array}$ & $\begin{array}{r}42 \\
117 \\
23 \\
55 \\
55 \\
62 \\
66 \\
493\end{array}$ & $\begin{array}{r}3 \\
3.3 \\
1.44 \\
1.61 \\
3.74 \\
3.79 \\
2.43 \\
4.17\end{array}$ & $\begin{array}{l}0.56 \\
1.11 \\
0.36 \\
0.42 \\
1.04 \\
1.07 \\
0.63 \\
0.97\end{array}$ & $\begin{array}{r}1.87 \\
0.26 \\
4.42 \\
2.42 \\
1.18 \\
1.08 \\
3.29 \\
4.41 \\
18.93\end{array}$ & $\begin{array}{r}-0.06(-0.62,0.5) \\
0.16(-1.66,1.98) \\
0.49(1.31,0.67) \\
0.44(-0.01,0.89) \\
-0.88(-1.66,-0.1) \\
-0.46(-1.28,0.36) \\
-0.32(-0.64,0) \\
-0.51(-0.69,-0.33) \\
-0.13(-0.56,0.3)\end{array}$ & 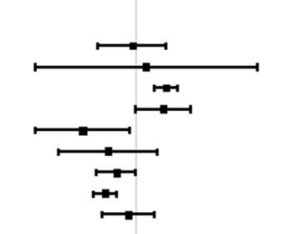 \\
\hline $\begin{array}{l}\text { TC } \\
\text { Periyasamy, S.(2017) } \\
\text { Periyasamy, S.(2017) } \\
\text { Singh, N.K.(2012) } \\
\text { Singh, N...(2012) } \\
\text { Cacabelos, R.(2004) } \\
\text { Cacabelos, R.(2004) } \\
\text { Moreno, J.A.(2004) } \\
\text { Pallaud,C. (2001) } \\
\text { Fernandes, M.A. (1999) } \\
\text { Fernandes, M.A. (1999) } \\
\text { Pooled WMD }\end{array}$ & $\begin{array}{r}5 \\
3 \\
4 \\
9 \\
4 \\
7 \\
10 \\
111 \\
3 \\
3\end{array}$ & $\begin{array}{r}4.84 \\
5.48 \\
3.75 \\
3.14 \\
4.87 \\
5.39 \\
3.78 \\
5.58 \\
5.5 \\
3.9\end{array}$ & $\begin{array}{l}0.54 \\
2.15 \\
0.51 \\
0.9 \\
0.78 \\
1.19 \\
0.49 \\
0.99 \\
1.1 \\
0.4\end{array}$ & $\begin{array}{r}42 \\
117 \\
23 \\
55 \\
55 \\
62 \\
66 \\
493 \\
24 \\
21\end{array}$ & $\begin{array}{r}4.99 \\
5.33 \\
3.48 \\
2.96 \\
5.7 \\
5.77 \\
4.09 \\
6.02 \\
4.9 \\
5\end{array}$ & $\begin{array}{r}0.63 \\
1.27 \\
0.62 \\
0.64 \\
1.16 \\
1.2 \\
0.67 \\
1.06 \\
1 \\
1\end{array}$ & $\begin{array}{l}2.11 \\
0.15 \\
1.88 \\
1.67 \\
1.07 \\
0.88 \\
3.13 \\
4.22 \\
0.49 \\
1.63 \\
17.23\end{array}$ & $\begin{array}{r}-0.15(-0.66,0.36) \\
0.15(-2.29,2.59) \\
0.27(-0.29,0.83) \\
0.18(-0.43,0.79) \\
-0.83(-1.65,-0.01) \\
-0.38(-1.31,0.55) \\
-0.31(-0.65,0.03) \\
-0.44(-0.65,-0.23) \\
0.6(-0.71,1.91) \\
-1.1(-1.72,-0.48) \\
-0.29(-0.54,-0.03)\end{array}$ & • \\
\hline $\begin{array}{l}\text { TG } \\
\text { Periyasamy, S.(2017) } \\
\text { Periyasamy, S.(2017) } \\
\text { Singh, N.K. (2012) } \\
\text { Singh, N... (2012) } \\
\text { Yan, L.(2005) } \\
\text { Cacabelos, R. (2004) } \\
\text { Cacabelos, R.(2004) } \\
\text { Moreno, J.A.(2004) } \\
\text { Pallaud,C. (2001) } \\
\text { Fernandes, M.A.(1999) } \\
\text { Fernandes, M.A.(1999) } \\
\text { Pooled WMDD }\end{array}$ & $\begin{array}{r}5 \\
3 \\
4 \\
9 \\
25 \\
4 \\
4 \\
7 \\
10 \\
111 \\
3 \\
3\end{array}$ & $\begin{array}{r}1.79 \\
2.29 \\
1.33 \\
1.87 \\
1.34 \\
1.23 \\
1.33 \\
1.05 \\
1.27 \\
1.05 \\
1.2\end{array}$ & $\begin{array}{l}0.31 \\
0.81 \\
0.45 \\
0.6 \\
0.55 \\
0.38 \\
0.75 \\
0.43 \\
0.73 \\
0.2 \\
0.4\end{array}$ & $\begin{array}{r}42 \\
117 \\
23 \\
55 \\
123 \\
55 \\
62 \\
66 \\
493 \\
24 \\
21 \\
21\end{array}$ & $\begin{array}{r}1.89 \\
2.1 \\
1.83 \\
1.7 \\
1.23 \\
1.28 \\
1.35 \\
0.82 \\
1.28 \\
1.1 \\
0.9\end{array}$ & $\begin{array}{l}0.47 \\
0.54 \\
1.02 \\
0.57 \\
0.55 \\
0.87 \\
0.67 \\
0.45 \\
0.77 \\
0.5 \\
0.5\end{array}$ & $\begin{array}{l}3.42 \\
0.89 \\
1.69 \\
2.61 \\
3.98 \\
2.5 \\
1.79 \\
3.56 \\
4.65 \\
3.45 \\
2.16 \\
30.7\end{array}$ & $\begin{array}{r}-0.1(-0.41,0.21) \\
0.19(-.73,1.11) \\
-0.5(-1.11,0.11) \\
0.17(-0.25,0.59) \\
0.11(-13,0.35) \\
-0.05(-0.49,0.39) \\
-0.02(-0.6,0.56) \\
0.23(-0.06,0.52) \\
-0.01(-.16,0.14) \\
-0.05(-0.35,0.25) \\
0.3(-0.2,0.8) \\
0.03(-0.06,0.12)\end{array}$ & שே \\
\hline Total pooled WMD & & & & & & & 100 & $-0.06(-0.15,0.04)$ & 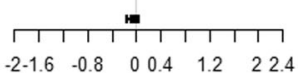 \\
\hline
\end{tabular}

Fig. 3 Overall circulating cholesterol levels for the comparisons of $A p o E$ gene $\varepsilon 2$ versus $\varepsilon 3$. Forest plots of circulating cholesterol levels associated with the $A p o E$ gene $\varepsilon 2 / \varepsilon 3 / \varepsilon 4$ alleles for $\varepsilon 2$ vs. $\varepsilon 3$ from the available studies.

HDL-C was $1.14^{52}$. Another study showed that a $1 \mathrm{mmol} /$ $\mathrm{L}$ increment in TC corresponded to a 4.58-times higher likelihood of developing hypertension, and the same increase in LDL-C corresponded to a 3.97-times higher likelihood ${ }^{24}$. Because genotypes are invariant over time and can exert an effect on circulating cholesterol levels over a lifetime.

As for the molecular mechanisms, there has been increasing evidence in basic medical research. Umeda et al. observed that hypercholesterolemia accelerates the intraneuronal accumulation of $\mathrm{A} \beta$ oligomers and subsequent synapse loss, thus resulting in memory impairment in $\mathrm{AD}$ mouse models ${ }^{53}$. Chen et al. found that increased levels of cholesterol affected the function and structure of endolysosomes, leading to the deposition of $A \beta$ and phosphorylated tau protein in the brain of $\mathrm{AD}$ rabbits ${ }^{54}$. A recent study also demonstrated that high cholesterol and 27hydroxycholesterol levels affect memory consolidation in experimental studies, suggesting that this cholesterol metabolite could link peripheral cholesterol to AD pathogenesis $^{55}$. In a meta-analysis, the use of statins was significantly associated with a reduced risk of all-caused dementia (adjusted RR $(\mathrm{aRR})=0.849,95 \%$ CI: 0.787-0.916) and $\mathrm{AD}(\mathrm{aRR}=0.719,95 \% \mathrm{CI}: 0.576 \text { to } 0.899)^{56}$. Another meta-analysis indicated that the use of statins might benefit all $\mathrm{AD}$ subjects $(\mathrm{HR}=0.80$; 95\% CI: $0.68-0.95)$ and may be most beneficial in subjects with an ApoE $\varepsilon 4 / 4$ genotype $^{57}$. Together, these studies strongly suggest that increased levels of circulating cholesterol play an important role in the pathogenesis of $\mathrm{AD}$. Consequently, these studies suggested that increased levels of circulating cholesterol might play a causal role in the pathogenesis of $\mathrm{AD}$.

Despite the strengths of this meta-analysis, some possible limitations should be acknowledged. Firstly, because we retrieved published literatures in English, selective publication bias could not be ruled out completely. Secondly, we only focused on the $A p o E$ gene $\varepsilon 2 / \varepsilon 3 / \varepsilon 4$ polymorphism as well as did not cover other candidate genes or polymorphisms in this gene, which might restrict the statistical power. Thirdly, the cholesterol levels were measured only once for almost all eligible studies which could not reflect the long-term cholesterol profiles in the development of dementia. Fourthly, this meta-analysis was conducted with the use of summarized data rather 


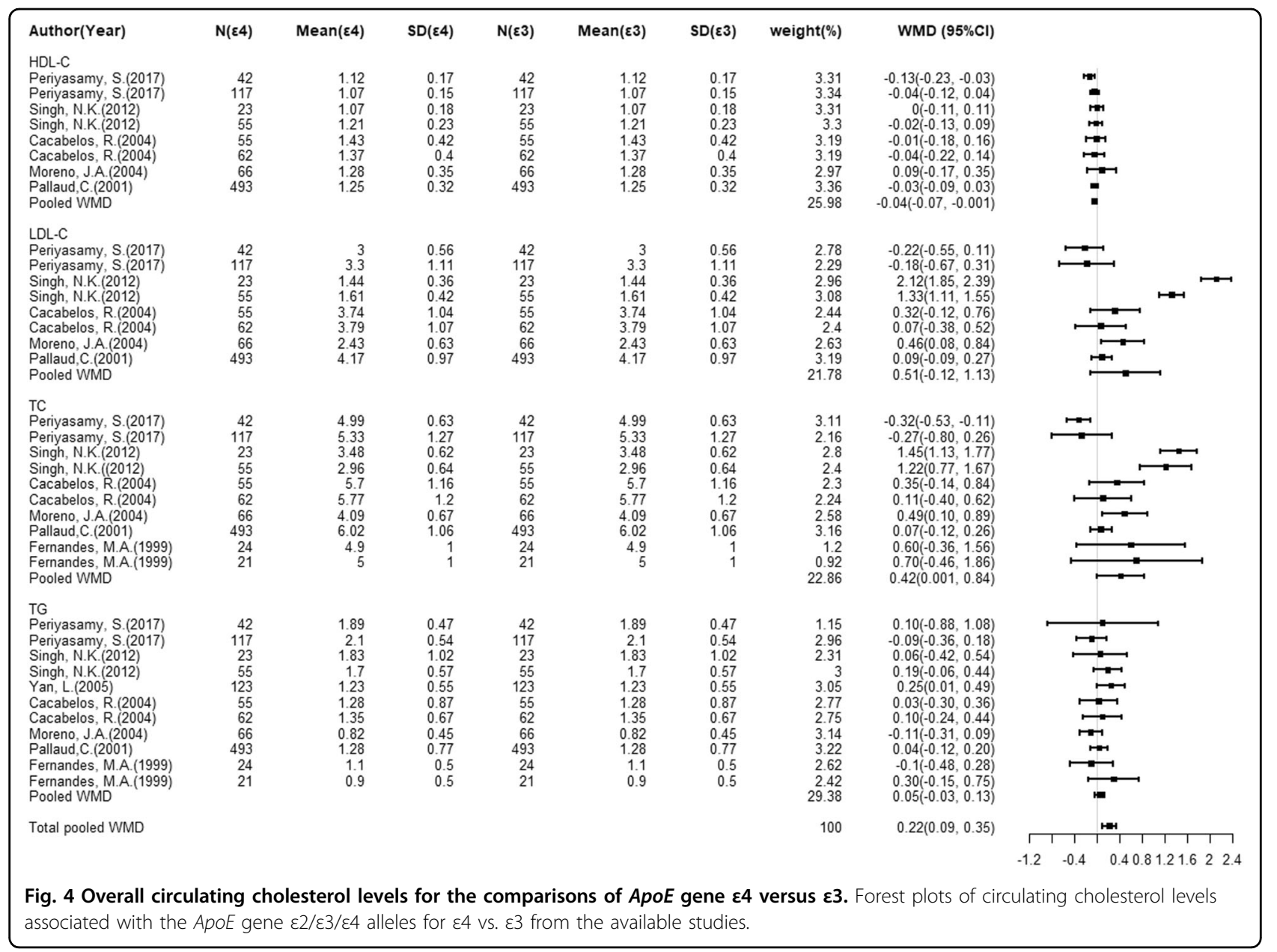

than individual participant data, with age-stratified, homozygous and heterozygous genotypes analyses unavailable. Fifthly, an essential requirement of $M R$ was that a pleiotropic effect of the ApoE gene $\varepsilon 2 / \varepsilon 3 / \varepsilon 4$ polymorphism was not be calculated and might beyond the capability to eliminate this effect in this meta-analysis. Therefore, a solid conclusion could not be produced from this metaanalysis which should be treated cautiously, until large, well-designed, prospective studies confirm our findings.

In conclusion, our results indicate that reduced circulating HDL-C and increased TC levels may be potential risk factors for dementia. Our findings in this study are promising for future practical applications.

\section{Acknowledgements}

The study was supported by grants from the National Key R\&D Program of China (2017YFE0118800)-European Commission Horizon 2020 (779238-PRODEMOS), the National Natural Science Foundation of China (81872682 and 81773527), and the China-Australian Collaborative Grant (NSFC 81561128020-NHMRC APP1112767).

\section{Author details}

'Department of Epidemiology and Health Statistics, School of Public Health, Beijing Municipal Key Laboratory of Clinical Epidemiology, Capital Medical University, Beijing 100069, China. ${ }^{2}$ Geriatric Department, Emergency General
Hospital, Beijing 100028, China. ${ }^{3}$ School of Public Health, Shandong First Medical University \& Shandong Academy of Medical Sciences, Tai'an 271000, China. ${ }^{4}$ Beijing Neurosurgical Institute, Capital Medical University, Beijing 100070, China. ${ }^{5}$ School of Medical and Health Sciences, Edith Cowan University, Perth, WA 6027, Australia

\section{Conflict of interest}

The authors declare that they have no conflict of interest.

\section{Publisher's note}

Springer Nature remains neutral with regard to jurisdictional claims in published maps and institutional affiliations.

Supplementary Information accompanies this paper at (https://doi.org/ 10.1038/s41398-020-0822-x).

Received: 6 August 2019 Revised: 21 April 2020 Accepted: 28 April 2020 Published online: 12 May 2020

\section{References}

1. Rao, A., Suliman, A., Vuik, S., Aylin, P. \& Darzi, A. Outcomes of dementia: Systematic review and meta-analysis of hospital administrative database studies. Arch. Gerontol. Geriatrics 66, 198-204 (2016).

2. Alva, G., Grossberg, G. T., Schmitt, F. A., Meng, X. \& Olin, J. T. Efficacy of rivastigmine transdermal patch on activities of daily living: item responder analyses. Int. J. Geriatr. Psychiatry 26, 356-363 (2011). 
3. Lesser, G. et al. Elevated serum total and LDL cholesterol in very old patients with Alzheimer's disease. Dement. Geriatr. Cogn. Disord. 12, 138-145 (2001).

4. Notkola, I. L. et al. Serum total cholesterol, apolipoprotein E epsilon 4 allele, and Alzheimer's disease. Neuroepidemiology 17, 14-20 (1998).

5. Jarvik, G. P. et al. Interactions of apolipoprotein E genotype, total cholesterol level, age, and sex in prediction of Alzheimer's disease: a case-control study. Neurology 45, 1092-1096 (1995).

6. Reitz, C., Tang, M. X., Luchsinger, J. \& Mayeux, R. Relation of plasma lipids to Alzheimer disease and vascular dementia. Arch. Neurol. 61, 705-714 (2004).

7. Tan, Z. S. et al. Plasma total cholesterol level as a risk factor for Alzheimer disease: the Framingham Study. Arch. Intern. Med. 163, 1053-1057 (2003).

8. Reitz, C. et al. A summary risk score for the prediction of Alzheimer disease in elderly persons. Arch. Neurol. 67, 835-841 (2010).

9. Chen, $\mathrm{H}$. et al. Association between serum cholesterol levels and Alzheimer's disease in China: a case-control study. Int. J. Food Sci. Nutr. 70, 405-411 (2019).

10. Reitz, C. et al. Association of higher levels of high-density lipoprotein cholesterol in elderly individuals and lower risk of late-onset Alzheimer disease. Arch. Neurol. 67, 1491-1497 (2010).

11. Brown, M. S., Kovanen, P. T. \& Goldstein, J. L. Regulation of plasma cholesterol by lipoprotein receptors. Science 212, 628-635 (1981).

12. Davignon, J. REG, and C F Sing. Apolipoprotein E polymorphism and atherosclerosis. Arteriosclerosis 8, 1-21 (1988)

13. Lambert, J. C. et al. Meta-analysis of 74,046 individuals identifies 11 new susceptibility loci for Alzheimer's disease. Nat. Genet 45, 1452-1458 (2013).

14. Dallongeville, J., Lussier-Cacan, S. \& Davignon, J. Modulation of plasma triglyceride levels by apoE phenotype: a meta-analysis. J. lipid Res. 33, 447-454 (1992).

15. Hanis, C. L., Hewett-Emmett, D., Douglas, T. C., Bertin, T. K. \& Schull, W. J. Effects of the apolipoprotein E polymorphism on levels of lipids, lipoproteins, and apolipoproteins among Mexican-Americans in Starr County, Texas. Arterioscler. Thromb. 11, 362-370 (1991).

16. Utermann, G. Apolipoprotein E polymorphism in health and disease. Am. Heart J. 113(2 Pt 2), 433-440 (1987).

17. Assmann, G., Schmitz, G., Menzel, H. J. \& Schulte, H. Apolipoprotein E polymorphism and hyperlipidemia. Clin. Chem. 30, 641-643 (1984).

18. Sorli, J. V. et al. The effect of the APOE polymorphism on HDL-C concentrations depends on the cholesterol ester transfer protein gene variation in a Southern European population. Clin. Chim. Acta 366, 196-203 (2006).

19. Maluf, D. G. et al. Apolipoprotein E genotypes as predictors of high-risk groups for developing hyperlipidemia in kidney transplant recipients undergoing sirolimus treatment. Transplantation 80, 1705-1711 (2005).

20. Song, Y., Stampfer, M. J. \& Liu, S. Meta-analysis: apolipoprotein E genotypes and risk for coronary heart disease. Ann. Intern. Med. 141, 137-147 (2004).

21. Zhang, M. D. et al. Apolipoprotein E gene polymorphism and risk for coronary heart disease in the Chinese population: a meta-analysis of 61 studies including 6634 cases and 6393 controls. PLOS ONE 9, e95463 (2014).

22. Abboud, S. et al. Associations of apolipoprotein $\mathrm{E}$ gene with ischemic stroke and intracranial atherosclerosis. Eur. J. Hum. Genet. 16, 955-960 (2008).

23. Ruixing, $Y$. et al. The environmental and genetic evidence for the association of hyperlipidemia and hypertension. J. Hypertens. 27, 251-258 (2009).

24. Niu, W., Zhang, X. \& Qi, Y. Association of an apolipoprotein E polymorphism with circulating cholesterols and hypertension: a meta-based Mendelian randomization analysis. Hypertension Res. 35, 434-440 (2012).

25. Davey Smith, G. \& Ebrahim, S. What can mendelian randomisation tell us about modifiable behavioural and environmental exposures? BMJ $\mathbf{3 3 0}$ 1076-1079 (2005).

26. David, M., Alessandro, L., Jennifer, T. \& Altman, D. G. Preferred reporting items for systematic reviews and meta-analyses: the PRISMA statement. Ann. Intern. Med. 151, 264-269 (2009).

27. Wells G. et al. The Newcastle-Ottawa Scale (NOS) for Assessing Quality of Nonrandomized Studies in Meta-analyses (Ottawa Health Research Institute, Ottawa, Canada, 2000).

28. Higgins, J. P. T., Thompson, S. G., Deeks, J. J. \& Altman, D. G. Measuring inconsistency in meta-analyses. BMJ 327, 557-560 (2003).

29. Shafagoj, Y. A. et al. APOE Gene polymorphism among Jordanian Alzheimer's patients with relation to lipid profile. Neuroscience 23, 29-34 (2018).

30. Wang, $C$. et al. High thiamine diphosphate level as a protective factor for Alzheimer's disease. Neurol. Res. 40, 658-665 (2018).

31. Sery, O. et al. CD36 gene polymorphism is associated with Alzheimer's disease. Biochimie 135, 46-53 (2017).
32. Lara, V. P. et al. Cortisol, HDL-C, VLDL-C, and APOE polymorphisms as laboratorial parameters associated to cognitive impairment no dementia (CIND) and dementia. J. Clin. Lab. Anal. 30, 374-380 (2016).

33. Agarwal, R., Talwar, P. Kushwaha, S. S., Tripathi, C. B. \& Kukreti, R. Effect of apolipoprotein e (APO E) polymorphism on leptin in Alzheimer's disease. Ann. Indian Acad. Neurol. 18, 320-326 (2015).

34. de-Almada, B. V. et al. Protective effect of the APOE-e3 allele in Alzheimer's disease. Braz. J. Med. Biol. Res. 45, 8-12 (2012).

35. Singh, N. K. et al. Gene-environment interaction in Alzheimer's disease. Am. J. Alzheimer's Dis. 27, 496-503 (2012).

36. Warren, M. W., Hynan, L. S. \& Weiner, M. F. Lipids and adipokines as risk factors for Alzheimer's disease. J. Alzheimer's Dis. 29, 151-157 (2012).

37. Styczynska, M. et al. Association between genetic and environmental factors and the risk of Alzheimer's disease. Folia Neuropathol. 46, 249-254 (2008).

38. Bednarska-Makaruk, M. et al. Antibodies against oxidized LDL and apolipoprotein E polymorphism in demented patients. J. Neurol. Sci. 283, 137-138 (2009).

39. Pandey, P., Pradhan, S. \& Mittal, B. Presenilin gene predisposes to late-onset degenerative but not vascular dementia: a comparative study of PS1 and ApoE genes in a North Indian Cohort. Dement. Geriatr. Cogn. Disord. 24, 151-161 (2007)

40. Jasinska-Myga, B. et al. Apolipoprotein E gene polymorphism, total plasma cholesterol level, and Parkinson disease dementia. Arch. Neurol. 64, 261-265 (2007).

41. Raygani, A. V., Rahimi, Z., Kharazi, H., Tavilani, H. \& Pourmotabbed, T. Association between apolipoprotein $\mathrm{E}$ polymorphism and serum lipid and apolipoprotein levels with Alzheimer's disease. Neurosci. Lett. 408, 68-72 (2006).

42. Periyasamy, S. et al. Association Studies of specific cholesterol related genes (APOE, LPL, and CETP) with lipid profile and memory function: a correlative study among rural and tribal population of Dharmapuri District, India. J. Alzheimer's Dis. 60(s1), S195-s207 (2017).

43. Cacabelos, R. et al. Phenotypic profiles and functional genomics in Alzheimer's disease and in dementia with a vascular component. Neurological Res. 26, 459-480 (2004).

44. Moreno, J. A. et al. The effect of dietary fat on LDL size is influenced by apolipoprotein E genotype in healthy subjects. J. Nutr. 134, 2517-2522 (2004).

45. Pallaud, C. et al. Genetic influences on lipid metabolism trait variability within the Stanislas Cohort. J. Lipid Res. 42, 1879-1890 (2001).

46. Fernandes, M. A. et al. Effects of apolipoprotein E genotype on blood lipid composition and membrane platelet fluidity in Alzheimer's disease. Biochim. Biophys. Acta 1454, 89-96 (1999).

47. Yan, L. et al. Effect of apolipoprotein E genotype on vitamin $\mathrm{K}$ status in healthy older adults from China and the UK. Br. J. Nutr. 94, 956-961 (2005).

48. Mielke, M. M. et al. The 32-year relationship between cholesterol and dementia from midlife to late life. Neurology 75, 1888-1895 (2010).

49. Yang, $\mathrm{C}$. et al. Causal relevance of circulating high-density lipoprotein cholesterol with cancer: a Mendelian randomization meta-analysis. Sci. Rep. 5, 9495 (2015).

50. Boulenouar, $\mathrm{H}$. et al. Impact of APOE gene polymorphisms on the lipid profile in an Algerian population. Lipids Health Dis. 12, 155 (2013).

51. Cibeira, G. H. et al. Apolipoprotein E genetic polymorphism, serum lipoprotein levels and breast cancer risk: A case-control study. Mol. Clin. Oncol. 2, 1009-1015 (2014).

52. Dahl, M. et al. C reactive protein and chronic obstructive pulmonary disease: a Mendelian randomisation approach. Thorax 66, 197-204 (2011).

53. Umeda, T. et al. Hypercholesterolemia accelerates intraneuronal accumulation of Abeta oligomers resulting in memory impairment in Alzheimer's disease model mice. Life Sci. 91, 1169-1176 (2012).

54. Chen, X. et al. Endolysosome mechanisms associated with Alzheimer's disease-like pathology in rabbits ingesting cholesterol-enriched diet. J. Alzheimer's Dis. 22, 1289-1303 (2010).

55. Bjorkhem, I., Cedazo-Minguez, A., Leoni, V. \& Meaney, S. Oxysterols and neurodegenerative diseases. Mol. Asp. Med 30, 171-179 (2009).

56. Chu, C. S. et al. Use of statins and the risk of dementia and mild cognitive impairment: A systematic review and meta-analysis. Sci. Rep. 8, 5804 (2018).

57. Geifman, N., Brinton, R. D., Kennedy, R. E., Schneider, L. S. \& Butte, A. J. Evidence for benefit of statins to modify cognitive decline and risk in Alzheimer's disease. Alzheimer's Res. Ther. 9, 10 (2017). 